\title{
Expression of rTSß as a 5-fluorouracil resistance marker in patients with primary breast cancer
}

\author{
SHOU-JEN KUO ${ }^{1}$, HWEI-CHUNG WANG ${ }^{2}$, KUAN-CHIH CHOW $^{4}$, SHIOW-HER CHIOU ${ }^{5}$, \\ SHU-FEN CHIANG ${ }^{5}$, TZE-YI LIN ${ }^{3}$, I-PING CHIANG ${ }^{3}$ and DAR-REN CHEN ${ }^{1}$ \\ ${ }^{1}$ Department of Research, Surgical Research Laboratory, Chang-Hua Christian Hospital, Chang-Hua; \\ Departments of ${ }^{2}$ Surgery and ${ }^{3}$ Pathology, China Medical University Hospital, Taichung; \\ Graduate Institutes of ${ }^{4}$ Biomedical Sciences and ${ }^{5}$ Veterinary Microbiology, \\ National Chung Hsing University, Taichung, Taiwan, R.O.C.
}

Received July 19, 2007; Accepted October 11, 2007

\begin{abstract}
Expression of thymidylate synthase (TS) in tumor cells is frequently suggested as an important prognostic factor for patients scheduled for chemotherapy with 5fluorouracil (5-FU). However, clinical evidence does not fully support such an anticipation. We studied the expression of rTSß, a reverse orientation gene of TS, as a 5-FU resistance marker in patients with primary breast cancer. Expression of rTSß was examined in 129 patients with newly diagnosed breast cancer and five breast cancer cell lines by immunohistochemistry, immunocytochemistry and immunoblotting. Clinically, expression of rTS $\beta$ was found to correlate with survival of the patients $(\mathrm{p}=0.023)$ when patients received chemotherapeutic regimen containing 5-FU. In vitro, $\mathrm{rTS} \beta$ expression was found to correlate with 5-FU resistance in breast cancer cell lines. Notably, in the 5-FU-resistant cells, rTS $\beta$ was identified in the nucleus, whereas in the 5-FUsensitive cells, rTSß was found in the cytoplasm. Nuclear localization of $\mathrm{rTS} \beta$ was further found to be associated with protein farnesylation. Therefore, nuclear expression of rTS $\beta$ could be a novel 5-FU resistance marker in patients with primary breast cancer.
\end{abstract}

Correspondence to: Dr Dar-Ren Chen, Department of Research, Chang-Hua Christian Hospital, 135 Nanshiao Street, Chang-Hua 500, Taiwan, R.O.C.

E-mail: darren_chen@cch.org.tw

Dr Kuan-Chih Chow, Graduate Institute of Biomedical Sciences, National Chung Hsing University, 250 Kuo-Kuang Road, Taichung 40227, Taiwan, R.O.C.

E-mail: kcchow@dragon.nchu.edu.tw

Abbreviations: 5-FU, 5-fluorouracil; FTI, farnesyltransferase inhibitor; HAS, human serum albumin; rTS $\alpha, \alpha$ form of antisense TS; rTS $\beta, \beta$ form of antisense TS; TS, thymidylate synthase

Key words: drug resistance, 5-fluorouracil, rTSß, nuclear localization, farnesylation, enolase

\section{Introduction}

Breast cancer is the second most prevalent malignancy and the fourth leading cause of cancer death in Taiwanese women (1). Although the death rate of uterine cervical cancer has decreased significantly in the past two decades due to the improvement in the early detection of the disease by pap smear among women over 35 years of age; for breast cancer, not only has the incidence increased markedly, but also the age of tumor occurrence has decreased dramatically, which is about ten years younger than that of the Western population (2-4).

Clinically, depending upon the status of estrogen and/or progesterone receptors in cancer cells, some patients receive non-steroidal anti-estrogen tamoxifen for hormonal therapy (5). However, most of the patients could only choose adjuvant chemotherapy containing 5-fluorouracil (5-FU) after surgery. 5 -FU is a pro-drug that is converted to fluorouridine to interfere with RNA synthesis, or to 5-fluoro-2'-deoxyuridine5'-monophosphate (FdUMP) to inhibit thymidylate synthase (TS) and the consequent DNA synthesis. In the presence of $\mathrm{N}^{5}$, ${ }^{10}$-methylene tetrahydrofolate, FdUMP further forms a stable ternary complex with TS to inhibit synthesis of deoxythymidine monophosphate (dTMP) (reviewed in ref. 6). TS expression in tumor cells is considered as a key prognostic factor for patients receiving chemotherapy containing 5-FU (7).

However, clinical evidence did not fully support this expectation (6,8-13). On the other hand, expression of the $r T S$ (ENOSF1) gene (14-16) was found to be closely associated with 5-FU sensitivity besides nucleotide metabolism-related enzymes, e.g., thymidine phosphorylase, ribonucleotide reductase, uridine phosphorylase and thymidine kinase (1719) that directly affects pyrimidine synthesis in de novo or salvage pathways (11).

The $r T S$ is located with the TS gene on the same stretch of chromosome 18, but in the opposite direction. The two genes partially overlap at 3'-end of each genomic sequence. The $r T S$ gene consists of 17 exons, and by alternate splicing, mRNAs can be respectively translated into a $41 \mathrm{kDa}$ rTS $\alpha$ or a $47 \mathrm{kDa}$ rTSß protein, of which in the carboxyl end of both proteins a fragment of 340 amino acid residues is identical. Both rTS $\alpha$ 
and $\mathrm{rTS} \beta$ induce the down-regulation of TS in cultured cells (20).

In this study, we investigated the correlation between rTS 3 expression and clinical outcome of $5 \mathrm{FU}$-response. We further examined gene expression of TS and rTSß in five breast cancer cell lines. Our results showed that the nuclear level of rTSß was correlated not only with poor prognosis in patients with primary breast cancer, but also with increased drug resistance to 5-FU in vitro.

\section{Materials and methods}

Materials, cell culture and drug treatment. Culture media and fetal calf serum (FCS) were from Gibco Laboratories (Grand Island, NY). All other materials were reagent grade from Sigma (St. Louis, MO) and Merck (Darmstadt, Germany). Antibodies were provided by Cashmere (Taipei, Taiwan). Breast cancer cells, 60055, BT-20, MCF-1, MCF-7 and T47D, were grown as a monolayer in RPMI-1640 plus $10 \%$ FCS. H630 and H630-1 cells were grown as previously described (14-16). Except as noted otherwise, cultured cells were incubated at $37^{\circ} \mathrm{C}$ and all media were supplemented with penicillin $(100 \mathrm{IU} / \mathrm{ml})$ and streptomycin $(100 \mu \mathrm{g} / \mathrm{ml})$.

Patients. From January 1996 to October 2003, tissue specimens from 129 patients with newly diagnosed breast cancer were collected. All patients were pathologically confirmed with breast cancer. Both the primary tumor and the corresponding non-tumor tissue were obtained from patients who had undergone surgical resection. The stage of disease progression was classified according to the Tumornode-metastasis system. For patients at stage III or beyond, post-operative adjuvant chemotherapy, which contained cyclophosphamide, methotrexate and 5-fluorouracil commenced within one month if the patient's condition was suitable. After treatment, all patients were followed as routine. Written informed consent was obtained from every patient.

Immunocytochemical, immunohistochemical and immunoblotting analyses. Immunological staining was performed according to the immunoperoxidase method reported by Chiou et al (21). Briefly, immunohistochemistry was performed on paraffin sections of the biopsy using the LSAB method (Dako, Carpenteria, CA). The chromogenic reaction was visualized by peroxidase-conjugated streptavidin (Dako) and aminoethyl carbazole (Sigma). Slides were counterstained with Mayor's hematoxylin, and the positive staining was recognized as crimson-red granules under a light microscope. For immunofluorescence staining, cellular uptake of MitoTracker ${ }^{\circledR}$ green FM (Molecular Probes, Inc., Eugene, OR) was used to label mitochondria. The cells were then fixed with $4 \%$ formaldehyde at room temperature for $15 \mathrm{~min}$. After washing three times with PBS, the cells were incubated with the primary antibodies for $90 \mathrm{~min}$, and washed three times with PBS. The secondary antibodies used were rhodamine (TRITC)-conjugated rabbit anti-mouse IgG (Jackson ImmunoResearch Laboratories, Inc., West Grove, PA). The slide was examined and the photo images were captured on a laser scanning confocal microscope (LSM510, Zeiss, Chicago, IL).
The method for immunoblotting analysis was described previously (22). Briefly, $5 \times 10^{6}$ cells were washed with phosphate buffered saline (PBS) (100 $\mathrm{mM} \mathrm{Na}_{2} \mathrm{HPO}_{4}, \mathrm{pH} 7.4$, $136 \mathrm{mM} \mathrm{NaCl}$ ) twice and lysed in a loading buffer [50 mM Tris (pH 6.8), $150 \mathrm{mM} \mathrm{NaCl}, 1 \mathrm{mM}$ disodium EDTA, $10 \%$ glycerol, $1 \mathrm{mM}$ phenylmethylsulfonylfluoride (PMSF), $0.01 \%$ bromophenol blue, 5\% ß-mercaptomethanol and 1\% SDS supplemented with trypsin inhibitor $(10 \mu \mathrm{g} / \mathrm{ml})]$. Electrophoresis was carried out using $10 \%$ polyacrylamide gels with $4.5 \%$ stacking gels. After electrophoresis, proteins were transferred to a nitrocellulose membrane. The membrane was then probed with antibodies specific to rTSß protein or farnesylated human serum albumin (HSA). The signal was amplified by biotin-labeled goat anti-mouse IgG, and peroxidase-conjugated streptavidin. The presence of protein was visualized by exposing the membrane to X-Omat film (Eastman Kodak, Rochester, NY) with enhanced chemiluminescent reagent (Pierce, Rockford, IL). In each case, normal breast tissue served as an internal negative control.

Slide evaluation. Slides were read by three independent pathologists without prior clinicopathological knowledge. A specimen was considered positive if $>10 \%$ of the cancer cells were positively stained; and negative if $<10 \%$ of the cells were positive (23).

Cytotoxicity assay. Cytotoxicity was determined by a modified MTT method, in which the activity of mitochondrial dehydrogenase was used as a measure. Cells were seeded at $1000,2500,5000$, and 10000 cells/well $18 \mathrm{~h}$ prior to drug challenge. The cells were then continuously treated with various concentrations of 5-FU (ranging from 1.6 to $1.0 \mathrm{mM}$ ) for $72 \mathrm{~h}$. The control group was treated with PBS only. Following drug challenge, $10 \mu \mathrm{l}$ of WST-1 (BioVision, Mountain View, CA) was added and incubation was continued for two hours. The percentage survival of cells was quantified by being compared to the control group. All procedures were performed in triplicate.

Preparation of nuclear extract. The procedure for preparing nuclear extracts was described previously (24). Briefly, monolayer cells $\left(2-5 \times 10^{7}\right)$ grown to $70 \%$ confluence were detached with trypsin-EDTA. Following washes with PBS and solution A [20 mM Hepes, pH 7.5, $5 \mathrm{mM} \mathrm{KCl,} 0.5 \mathrm{mM}$ $\mathrm{MgCl}_{2}, 0.5 \mathrm{mM}$ dithiothreitol (DTT), and $0.2 \mathrm{mM}$ sucrose], cell pellets were re-suspended into $2 \mathrm{ml}$ of ice cold hypotonic solution B [20 mM Hepes (pH 7.5), $5 \mathrm{mM} \mathrm{KCl,} \mathrm{0.5} \mathrm{mM}$ $\mathrm{MgCl}_{2}, 0.5 \mathrm{mM}$ DTT, and $1 \mathrm{mM}$ PMSF] and incubated on ice for $10 \mathrm{~min}$. The cell suspension was then placed in a Dounce homogenizer and subjected to 10 strokes with pestle $\mathrm{B}$, followed by centrifugation at $4^{\circ} \mathrm{C}, 2,000 \mathrm{xg}$ for $10 \mathrm{~min}$. The supernatant (cytoplasmic extract) was collected and the pellet was re-suspended into $3 \mathrm{ml}$ of solution $\mathrm{C}[20 \mathrm{mM}$ Hepes (pH 7.5), $2 \mathrm{mM} \mathrm{MgCl}_{2}, 1 \mathrm{mM}$ DTT, $1 \mathrm{mM}$ PMSF, and $0.25 \mathrm{mM}$ sucrose]. The nuclear suspension was layered over $3 \mathrm{ml}$ of solution D [20 mM Hepes ( $\mathrm{pH} 7.5), 2 \mathrm{mM}$ $\mathrm{MgCl}_{2}, 1 \mathrm{mM}$ DTT, $1 \mathrm{mM}$ PMSF and $0.6 \mathrm{mM}$ sucrose] before being centrifuged at $4^{\circ} \mathrm{C}, 15,000 \mathrm{x}$ g for $30 \mathrm{~min}$. The nuclear pellet was re-suspended into $0.75 \mathrm{ml}$ of solution $\mathrm{E}$ (50 mM Hepes, pH 7.5 and $10 \%$ sucrose), and the nuclear 


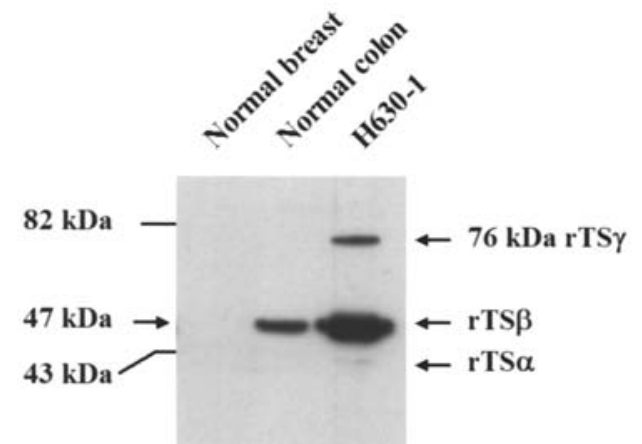

Figure 1. Immunological characterization of monoclonal antibodies to rTSB. Normal breast and colon were resected as non-tumor counterparts from patients with breast cancer or colon cancer. Colon cancer cell, H630-1, extract was used as a positive control. The antibodies also interact with a $43 \mathrm{kDa}$ protein $(\mathrm{rTS} \alpha)$ and a $76 \mathrm{kDa}$ protein $(\mathrm{rTS} \gamma)$. However, the signals of rTS $\alpha$ and rTS $\gamma$ proteins are much weaker than that of rTS $\beta$.

preparation was incubated with $0.3 \mathrm{M}$ of $\mathrm{NaCl}$ on ice for $30 \mathrm{~min}$. After centrifugation at $4^{\circ} \mathrm{C}, 15,000 \mathrm{x}$ g for $30 \mathrm{~min}$, the supernatant was saved as a nuclear extract.

Statistical analysis. Relations between rTSß expression and clinicopathological parameters were analyzed using the Chi-square test. When the expected number of any analysis was smaller than or equal to five cases, Fisher's exact test was used. Coefficient of rank correlation between rTSß expression and other factors were analyzed by Spearman rank correlation, in which the rank correlation coefficient ranges between -1 and 1 . Survival curves were plotted with the Kaplan-Meier method (25), and the statistical difference of survival between different groups was compared by the logrank test (26). Statistical analysis was performed using GraphPad Prism4 statistical software (San Diego, CA). A $\mathrm{P}$-value of $<0.05$ was considered as statistically significant.

\section{Results}

Characterization of antibodies to $r T S \beta$. Titer of antibodies was measured by enzyme-linked immunosorbent assay (ELISA). Specificity of the antibodies was determined by immunoblotting in order to recognize a $47 \mathrm{kDa}$ band in a whole cell lysate of cancer cells (Fig. 1). A $76 \mathrm{kDa}$ protein band was frequently detected in drug-resistant H630-1 colon cancer cells (16).

Expression of rTS $\beta$ in breast cancer cells and the correlation with survival in patients with primary breast cancer. Expression of $r T S$ was first examined by immunoblot analysis in the primary breast cancers, and rTS $\beta$ was mainly detected in the tumor fraction (Fig. 2A). However, no rTS $\alpha$ or rTS $\gamma$ was detected in these breast cancer specimens. Pathologically, 58 patients $(45.0 \%)$ were positive for rTSß expression as determined by immunohistochemistry (Fig. 2B). Notably, among these patients, nuclear $\mathrm{rTS} \beta$ was detected in $35(27.1 \%)$ of the specimens (Fig. 2B, right panel). Clinically, the median follow-up period for the patients was 30 months, ranging from 2.0 to 84 months. Mean age of the patients was 52.0 years (24 - 67 years). Statistical differences between
A

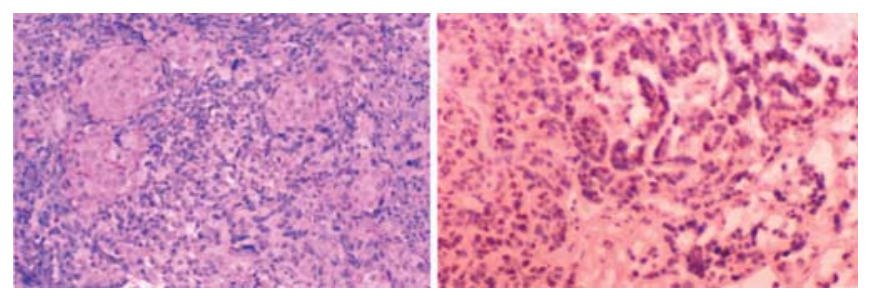

B

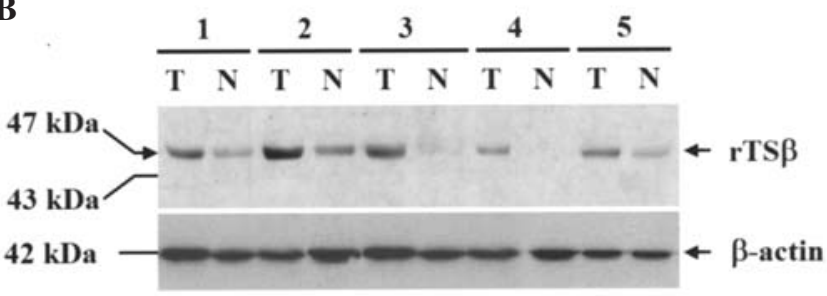

C

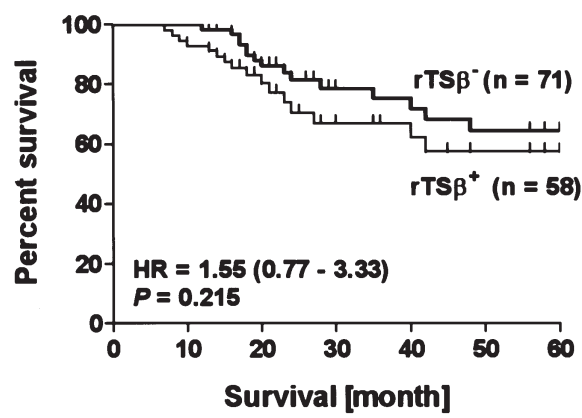

D

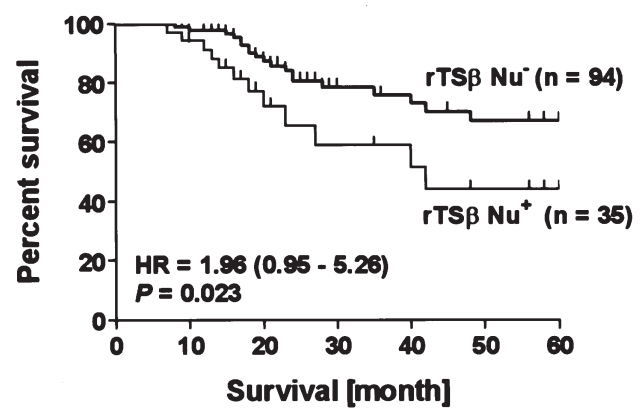

Figure 2. Expression of rTSß and patients' survival. (A) Immunohistochemical staining. Left panel: rTSß in cytoplasm. Right panel: rTSß in nuclei (original magnification x200). (B) Detection of rTSß by immunoblotting. T: tumor fraction, N: non-tumor counterpart. Survival difference between patient groups that were divided by $(C)$ expression of $\mathrm{rTS} \beta$ or not $(\mathrm{P}=0.215)$, or (D) the presence of nuclear $r T S \beta(P=0.023)$ or not. $r T S \beta \mathrm{Nu}^{+}$: the presence of nuclear rTSß in cancer cells, rTSß Nu: rTSß was present in the cytoplasm of the cancer cells.

patients with and those without nuclear rTS $\beta$ expression were found to be significant with respect to patients' age $(p=0.029)$, tumor stage $(\mathrm{p}=0.01)$, lymph node involvement $(\mathrm{p}=0.034)$, presence of estrogen and/or progesterone receptor $(\mathrm{p}=0.03)$, and status of Her-2/neu gene amplification $(\mathrm{p}<0.001)$ (Table I). Following surgery, 26 patients had tumor recurrence within 36 months. Among the 35 patients who had nuclear rTSß expression, $12(34.3 \%)$ patients had tumor recurrence. Among the 94 patients who had only cytoplasmic rTSß expression, 14 (14.9\%) patients had tumor recurrence. The difference was 
Table I. Correlation of rTSß expression with clinicopathological parameters.

\begin{tabular}{|c|c|c|c|}
\hline \multirow[t]{2}{*}{ Clinicopathological parameter } & \multicolumn{2}{|c|}{ Nuclear rTSß expression } & \multirow[b]{2}{*}{ P-value } \\
\hline & No $(n=94)$ & Yes $(n=35)$ & \\
\hline Age $(y r)(n=129)$ & $53.4 \pm 7.9$ & $48.2 \pm 7.3$ & $0.001^{\mathrm{a}}$ \\
\hline$\geq 45(n=57)$ & 47 & 10 & $0.029^{\mathrm{b}}$ \\
\hline$<45(\mathrm{n}=72)$ & 47 & 25 & \\
\hline \multicolumn{4}{|l|}{ Tumor size } \\
\hline $\mathrm{T} 1(\mathrm{n}=17)$ & 15 & 2 & $0.01^{\mathrm{b}}$ \\
\hline $\mathrm{T} 2(\mathrm{n}=68)$ & 54 & 14 & \\
\hline$\geq \mathrm{T} 3(\mathrm{n}=44)$ & 25 & 19 & \\
\hline \multicolumn{4}{|l|}{ Lymph node involvement } \\
\hline N0 $(n=43)$ & 38 & 5 & $<0.005^{\mathrm{b}}$ \\
\hline $\mathrm{N} 1-3(\mathrm{n}=86)$ & 56 & 30 & \\
\hline \multicolumn{4}{|l|}{ Nuclear grading } \\
\hline $1(n=9)$ & 8 & 1 & $0.056^{\mathrm{b}}$ \\
\hline $2(n=46)$ & 38 & 8 & \\
\hline $3(n=74)$ & 48 & 26 & \\
\hline \multicolumn{4}{|l|}{$\mathrm{ER} / \mathrm{PR}$} \\
\hline $\mathrm{ER}^{+} / \mathrm{PR}^{+}(\mathrm{n}=78)$ & 52 & 26 & $0.03^{\mathrm{b}}$ \\
\hline $\mathrm{ER}^{+} / \mathrm{PR}^{-}$or $\mathrm{ER}^{-} / \mathrm{PR}^{+}(\mathrm{n}=14)$ & 9 & 5 & \\
\hline $\mathrm{ER}^{-} / \mathrm{PR}^{-}(\mathrm{n}=37)$ & 33 & 4 & \\
\hline \multicolumn{4}{|l|}{ Copies of HER-2/neu gene ${ }^{c}$} \\
\hline $3-5$ or $>5(n=45)$ & 23 & 22 & $<0.001^{\mathrm{b}}$ \\
\hline $2(n=84)$ & 71 & 13 & \\
\hline
\end{tabular}

${ }^{a}$ Two-sided p-value determined by the t-test. ${ }^{b}$-value determined by the $\chi^{2}$ test. When the expected number of any analysis was smaller than or equal to five cases, the Fisher's exact test was used. 'Copies of HER-2/neu gene were determined by fluorescent in situ hybridization using probes from Vysis, Inc. (Downers Grove, IL).

A

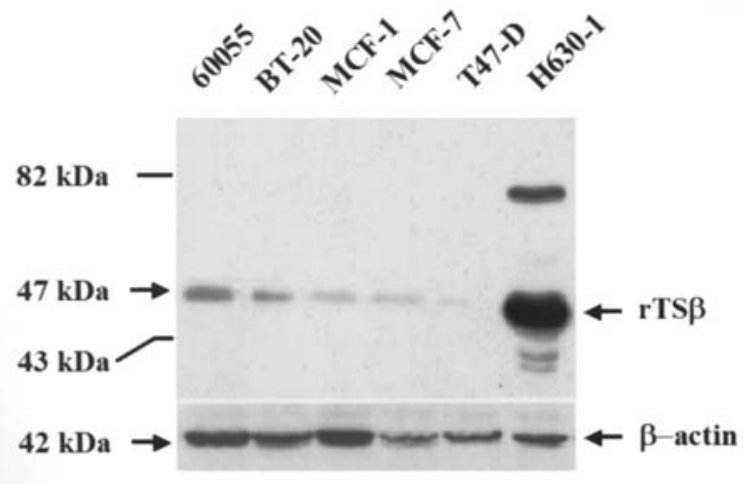

B

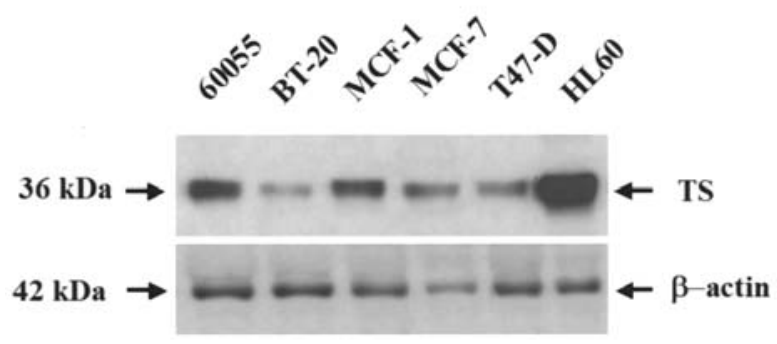

Figure 3. Expression levels of rTSß and TS proteins in breast cancer cell lines. (A) Protein $(40 \mu \mathrm{g})$ from the indicated cell lines was separated by gel electrophoresis and blotted as described. H630-1 was used as a positive standard. (B) Expression of TS protein; HL-60 cells were used as a positive standard to show the $36 \mathrm{kDa}$ TS protein.

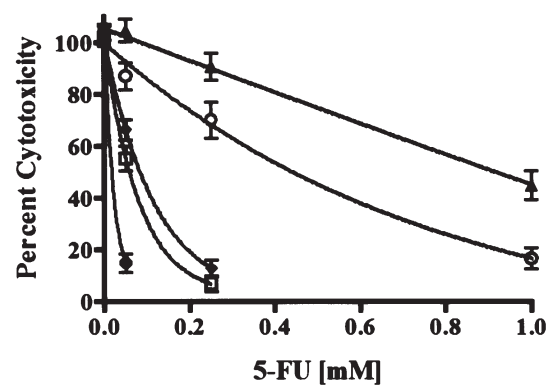

Figure 4. Sensitivity of breast cancer cells to 5-fluorouracil. Percent survival is plotted as a function of 5-FU concentration. Survival curves are the mean of triplicate experiments. $\Delta$ : BT-20, ○: 60055, $\bullet$ MCF-7, $\square$ MCF-1, ๑: T47D.

significant $(\mathrm{p}=0.015)$. These results clearly showed that in addition to age, expression of nuclear rTSß was correlated with advanced tumor stage, lymph node involvement, ER and/or PR expression and Her2-neu gene amplification in tumor cells. Although the difference between patient groups divided by total rTSß was not significant in survival analysis (Fig. 2C, $\mathrm{p}=0.215$ ), patients with nuclear $\mathrm{rTS} \beta$ had poorer survival, and the statistical difference was significant (Fig. 2D, $\mathrm{p}=0.023$ ). The median survival of patients with nuclear rTS $\beta$ was 42 months. These data suggest that expression of nuclear rTS $\beta$ is 


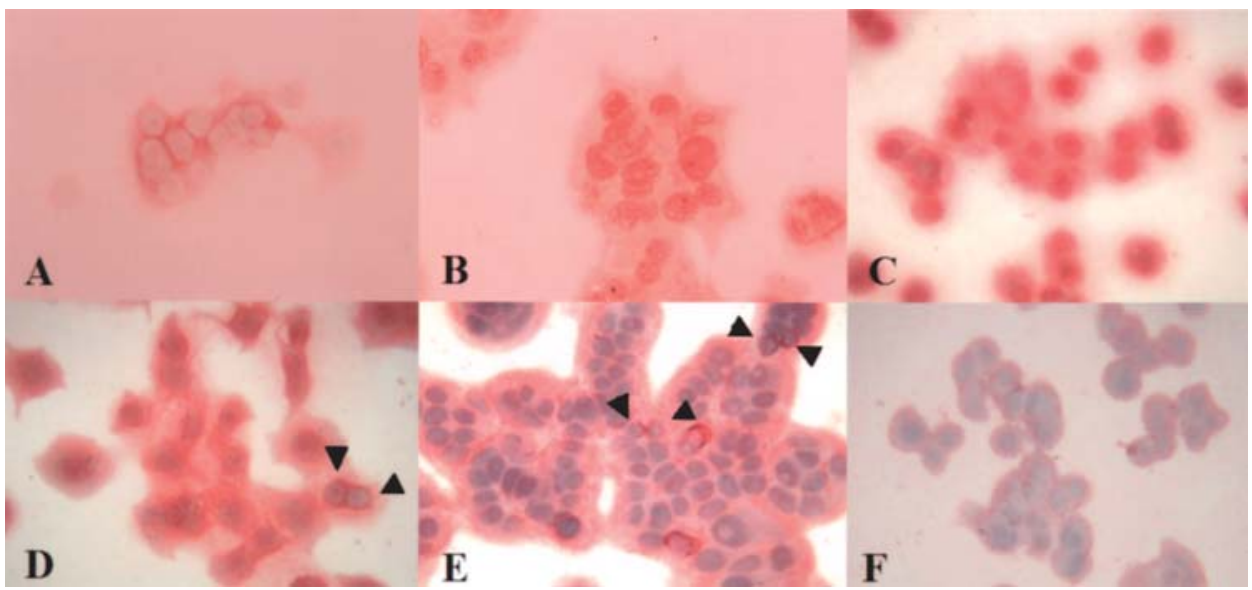

Figure 5. Differential localization of rTSß. (A) Expression of rTSß was detected in the cytoplasm of 5-FU-sensitive colon cancer cells H630. (B) rTSß protein was detected in the nuclei of 5-FU-resistant cells H630-1. (C) rTSß was found in the nuclei of 5-FU-resistant breast cancer cells H60055. (D) rTSß protein was located in the perinuclear region of the possibly post-mitotic BT-20 cells (arrows). (E) Perinuclear rTSß protein was also detected in the possibly postmitotic MCF-1 cells (arrows). (F) Expression of rTSß was barely detected in 5-FU-sensitive breast cancer cells T47D. Original magnification x200

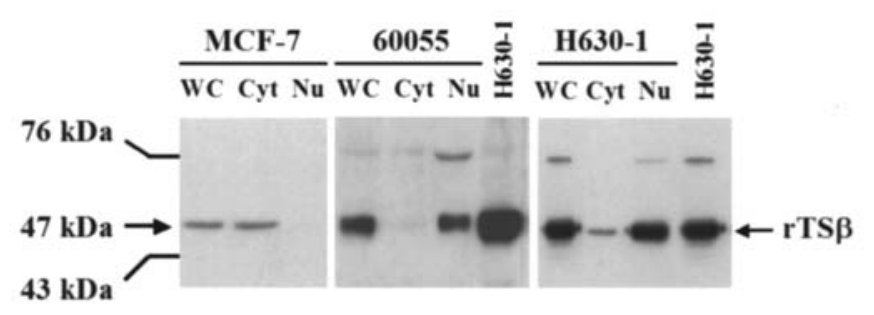

Figure 6. Subcellular distribution of rTSß. Following hypotonic treatment, cells were dounced to break the plasma membrane. Cytoplasmic and nuclear extracts were prepared as described and equal amounts $(40 \mu \mathrm{g})$ of protein were subjected to immunoblot analysis. WC: whole cell lysate, Cyt: cytoplasmic fraction, Nu: Nuclear extract, and H630-1 extract were used as a positive control

associated with poorer prognosis, which could be a result of drug resistance and early tumor recurrence.

Expression of $r T S \beta$ is associated with 5-FU resistance in breast cancer cells. As shown in Fig. 3A, protein level of rTSß varied among the breast cancer cell lines as determined by immunoblot analysis. Expression of rTSß was high in 60055 and BT-20, intermediate in MCF-1 and MCF-7 cells, and low in T47D cells. Expression of TS, however, was high in 60055 and MCF-1, and intermediate in the other three cell lines (Fig. 3B). Notably, resistance to 5-FU (BT-20> $60055>$ MCF-1 $=$ MCF-7 $>$ T47D) corresponded well to the level of rTSß, but not to that of TS in these cells (Fig. 4). The $\mathrm{IC}_{50}$ value of 5-FU in these cancer cells is $0.92 \mathrm{mM}$ for BT-20, $0.43 \mathrm{mM}$ for $60055,87 \mu \mathrm{M}$ for MCF-7, $52 \mu \mathrm{M}$ for MCF-1 and $8.3 \mu \mathrm{M}$ for T47D. Compared to T47D, the $\mathrm{IC}_{50}$ value of the other four cell lines is 6-110-fold higher.

Moreover, rTSß was identified in the nuclei of 5-FUresistant cell lines (H630-1, 60055 and BT20) by immunocytochemistry (Fig. 5B-D). In cells that are sensitive to 5-FU (MCF-1 and H630), rTSß was detected in the cytoplasm (Fig. 5A, E and F). In some BT-20 and MCF-1 cells, rTSß expression is perinuclear. These cells are probably post-mitotic as judged by the conjoining smaller nuclei (indicated by arrows in Fig. 5D and E).

To study the correlation of 5-FU resistance with rTSß location, we selected three cell lines, MCF-7, 60055, and H630-1, that had representative phenotypes with respect to 5-FU resistance. In addition to what is shown in Fig. 5, location of the rTS $\beta$ was determined by immunoblotting, and the results are shown in Fig. 6. For MCF-7, although the protein was located perinuclearly as determined by immunocytochemistry, it was not detected in the nuclear fraction. On the other hand, in 60055 and H630-1 cells, rTSß was identified in the nuclei by immunocytochemistry, and it was also predominantly detected in the nuclear fraction as determined by immunoblotting (Fig. 6). These data indicated that in 5-FU-resistant breast cancer and colon cancer cells, rTS $\beta$ was indeed located in the nuclei.

Farnesylation of rTS $\beta$ in 5-FU-resistant cancer cells. Besides the $76 \mathrm{kDa}$ protein band that was detected in H630-1 cells, no apparent difference in molecular weight of rTS $\beta$ from either the nucleus or cytoplasm was found. Post-translational modification with a small molecule was anticipated. Moreover, since protein farnesylation has been associated with nuclear translocation of large antigen (AgL) of hepatitis $\delta(\mathrm{HD})$ virus, farnesylation was expected as a potential modification of rTSß. Murine antibodies were therefore raised to recognize a $67 \mathrm{kDa}$ farnesylated human serum albumin (HAS) (lane 1, Fig. 7A) but not naked HSA (lane 2, Fig. 7A) (27). Antibodies specific to farnesylated HAS also recognized rTSß, which was precipitated from a nuclear extract of 60055 cells by monoclonal antibodies specific to rTSß (lane 4, Fig. 7A). Antibodies specific to farnesylated HAS did not react with rTSß (lane 3, Fig. 7A) from T47D, in which rTSß was located in the cytoplasm.

By immunocytochemistry, antibodies specific to farnesylated HAS recognized proteins in the nuclei of HDAgL-expressing Huh-7 cell (left panel, Fig. 7B) and in those of 5-FU-resistant H630-1 cells (center panel, Fig. 7B). No immunocytochemical signal was detected in 5-FU 
A

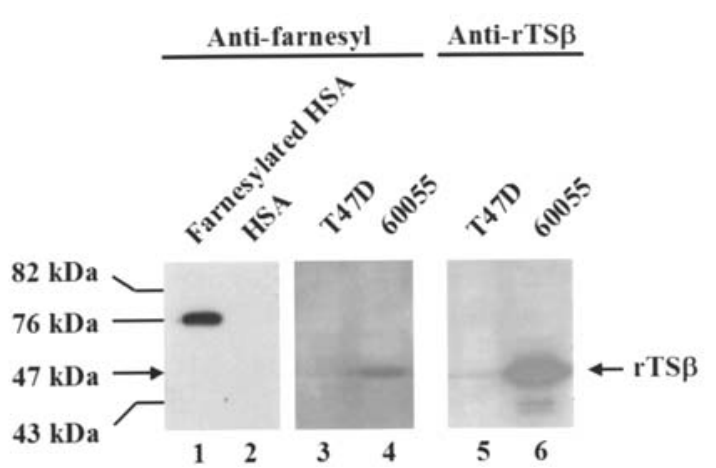

C

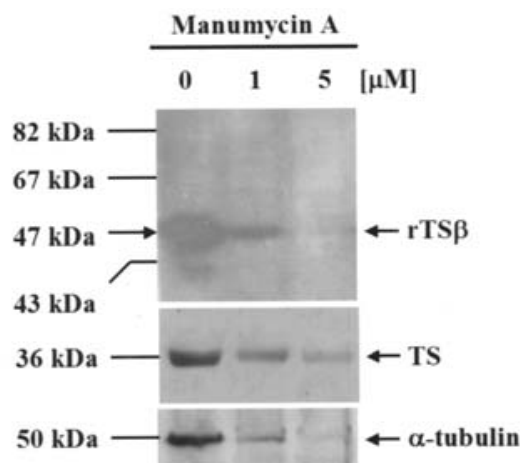

$\mathbf{E}$

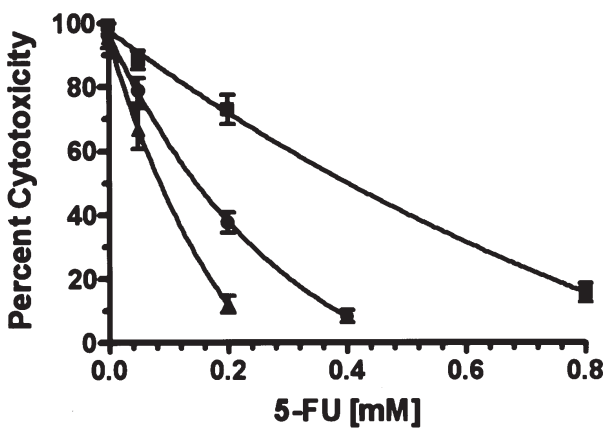

B

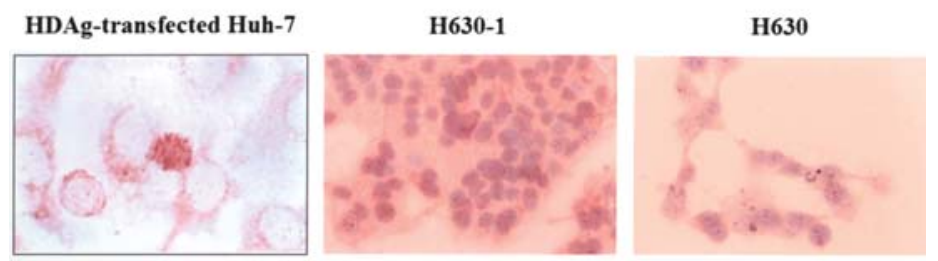

D

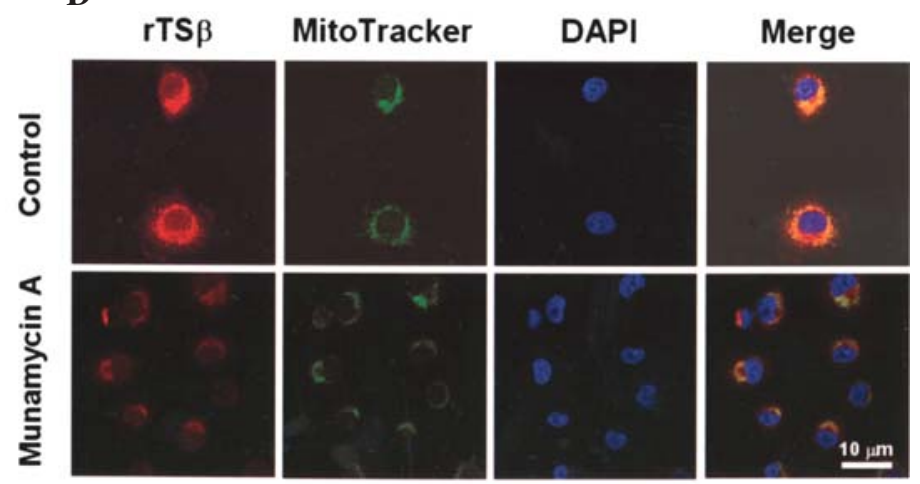

sensitive H630 cells (right panel, Fig. 7B). The addition of manumycin A, a farnesyltransferase inhibitor (FTI), significantly reduced expression (Fig. 7C) and nuclear level of rTSß (Fig. 7D). Treatment with manumycin A also reduced 5-FU resistance of the cancer cells (Fig. 7E).

\section{Discussion}

The data presented above showed that the presence of nuclear rTS $\beta$ in breast cancer correlated with patient survival, and patients with nuclear expression of $\mathrm{rTS} \beta$ protein had a significantly higher incidence of tumor recurrence and poorer prognosis. Results of the in vitro study further demonstrated that 5-FU-resistant cancer cells had a higher level of rTSß protein in the nucleus.

The biological presentation of $r T S$, which is located on the same stretch of chromosome, but in the opposite direction to the TS gene, has suggested its characteristics in counteracting TS gene expression (14). An in vitro study by Dolnick et al showed that cultured tumor cells with elevated $r T S$ gene
Figure 7. 5-FU-resistant rTSß is farnesylated. (A) Nuclear extract was immunoprecipitated with biotinylated antibodies to rTSß and streptavidinconjugated beads. The protein was released by tris-glycine $(\mathrm{pH} 2.3)$ before immunoblotting with rabbit antibodies to rTSß. (B) Farnesylated protein detected by immunocytochemistry. Left: HDAgL-transfected Huh-7 cells, center: 5-FU resistant H630-1 cells, and right: 5-FU sensitive H630 cells. (C) Manumycin A reduced rTSß expression in 60055 cells that were treated with 1 or $5 \mu \mathrm{M}$ of the drug for $20 \mathrm{~h}$ before harvest. (D) Treatment with manumycin A reduced nuclear localization of rTSß in 60055 cells as determined by confocal fluorescent immunomicroscopy. Antibodies to rTSB were labeled with rhodamine. MitoTracker (green) was mitochondriaspecific dye. Nuclei were stained with 4', 6-diamidino-2-phenylindole (DAPI). Merge: A merged image. (E) The effect of manumycin A on the sensitivity of breast cancer cells to 5-fluorouracil. Percent survival is plotted as a function of 5-FU concentration. Survival curves are the mean of triplicate experiments. $\mathbf{\square}: 60055$ cells, $\bullet$ : 60055 cells treated with $1 \mu \mathrm{M}$ manumycin A, $\mathbf{A}: 60055$ cells treated with $5 \mu \mathrm{M}$ manumycin $\mathrm{A}$.

expression are frequently associated with increased resistance to 5-FU and methotrexate (MTX) (15). They further demonstrated that rTSß could down-regulate TS expression, induce cell growth arrest and increase drug resistance in trans via the production of lipophilic metabolites of methionine or the effect of antisense RNA to TS (16). Although cell cycle arrest and 5-FU resistance are anticipated, the events that follow the generation of lipophilic metabolites are not well elucidated. Amino acid sequence analysis of rTSß shows that the enzyme may have motifs similar to L-alanine-DLglutamate epimerase and other enzymes of the enolase superfamily, which are closely associated with the biogenesis of the cell membrane (28). We confirmed their findings by showing that $\mathrm{rTS} \beta$ overexpression correlated with 5-FU resistance in both breast and colon cancer cells. Moreover, results of the immunocytochemistry and immunoblotting showed that $\mathrm{rTS} \beta$ was frequently detected in the nuclei and the nuclear level of rTSß was associated with 5-FU resistance. These results, however, did not fulfill the expected enzyme function. On the other hand, when 
considered together with clinical outcomes, our work suggested that the nuclear level of rTSß may not only be associated with increased 5-FU resistance, but also with a higher incidence of lymph node involvement, ER and/or PR expression, Her2-neu gene amplification and advanced tumor stage, events that are intimately associated with the rapid growth of breast cancer cells (14-16), and that rTSß may act as a nucleus-housed glycolytic protein, which may play a role during G2/M phases of cell cycle progression.

Studies by Spence et al (29) and Bugler et al (30) have shown that proteins, such as prostatic probasin and basic fibroblast growth factor (bFGF), behave differently when proteins are located in the different organelles. Moreover, Feo et al (31) demonstrated that $\alpha$-enolase, a glycolytic enzyme that catalyzes interconversion of 2-phosphoglycerate and phosphoenol-pyruvate in cytoplasm, could bind to the P2 promoter and function as a repressor for the transcription of $c$-myc oncogene. Notably, nuclear prostatic probasin, bFGF and $\alpha$-enolase are frequently truncated forms of the protein, which could expose the nuclear localization sequence (NLS) that is deeply embedded in the natural protein configuration $(29,32)$, or these proteins could be translated from an alternate initiation site to affix an extra peptide containing a NLS motif to N-terminus of the cognate protein (30). Moreover, because part of the rTS $\beta$ motif resembles enolase (28), it is therefore reasonable to suggest that rTS $\beta$ behaves like enolase having dual functions depending upon where the protein is located. However, in addition to organelle localization, no visible difference was found in molecular weight between nuclear and cytoplasmic rTSß.

The detection of farnesylated rTS $\beta$ in the nucleus indicated that isoprenylation of the protein might be responsible for nuclear transportation of the protein. The presence of rTS $\beta$ in the nucleus may then affect DNA replication and 5-FU sensitivity. Treatment with manumycin A, on the other hand, decreased expression and nuclear translocation of $\mathrm{rTS} \beta$. The addition of manumycin A also inhibits the protein level of TS and $\alpha$-tubulin, and such results suggest that farnesylation of rTSß could prevent protein degradation and maintain protein level in the cells (14-16). Moreover, our data indicated that like fatty acyl modification of the G-proteins, which help in determining the final destination of the protein either to the plasma membrane or to the endoplasmic reticulum to carry out the respective biological functions (32), farnesylation could also help in determining the organelle targeting of rTSß. The nucleus-translocated rTS $\beta$ is thus an important regulatory element for phenotype expression.

It is worth noting that treatment with manumycin A, which was designed to inhibit farnesylation of ras protein, increased 5-FU cytotoxicity. A study by Russo et al (33) suggested that FTI mediates an increase of 5-FU cytotoxicity via a p53dependent pathway. They further showed that the inactivation of p53 lowered FTI's effect on 5-FU toxicity (34). However, p53 is not a direct target of manumycin A. Inactivation of ras-GTPase, on the other hand, induces growth arrest and reduces DNA synthesis, which reflects on the decrease of 5FU cytotoxicity that is cell cycle-dependent (35).

Hussein and Taylor showed that farnesylation of kinetochore protein Cenp-F is required for cell cycle progression through $\mathrm{G} 2 / \mathrm{M}$ phases, and the reaction is crucial for preventing rapid protein turnover following mitosis (36). These observations supported our results, and clearly provided an explanation as to how FTIs affect cell growth in addition to p53 $(33,34)$. However, since no canonical CAAX sequence, a protein farnesylation signal (37), was identified at the $\mathrm{C}$-terminus of $\mathrm{rTS} \beta$, we are less certain that nuclear rTSß follows the traditional farnesylation process (37-39). Therefore, besides a quantitative difference in gene expression, qualitative change and different organelle localization of the individual gene product may also play an important role in determining the pathological activities of malignant cells, which in turn affects drug sensitivity and prognosis of the patients.

In conclusion, our data show that $\mathrm{rTS} \beta$ expression was frequently associated with poor prognosis in patients with primary breast cancer, especially in those with nuclear rTSß. In vitro, higher expression level of nuclear rTSß also correlated with lower 5-FU cytotoxicity of breast cancer cell lines. Compared to cytoplasmic rTS $\beta$, nuclear rTS $\beta$ was positive for farnesylation. These results suggest that expression of nuclear rTS $\beta$ could be an important factor in reflecting 5-FU resistance in patients with primary breast cancer, and nuclear localization of $\mathrm{rTS} \beta$ is farnesylation-dependent.

\section{Acknowledgements}

This study was supported by grants from the National Science Council (NSC95-2320-B-005-001, K.-C.C.) and Foundation of Chang-Hua Christian Hospital (95-CCH-KMU-39), Taiwan, R.O.C.

\section{References}

1. Annual reports of the Department of Health, the Executive Yuan, Republic of China, 2003.

2. Taiwan Cancer Organization Group, Cancer practices guideline of the National Health Research Institutes, Republic of China, 2003. (http://www.nhri.org.tw).

3. Chie WC, Chen CF, Lee WC, Chen CJ and Lin RS: Age-periodcohort analysis of breast cancer mortality. Anticancer Res 15: 511-515, 1995.

4. Chie WC, Chen CF, Chen CJ, Chang CL, Liaw YP and Lin RS: Geographic variation of breast cancer in Taiwan: international and migrant comparison. Anticancer Res 15: 2745-2749, 1995.

5. Fritz P, Murdter TE, Eichelbaum M, Siegle I, Weissert M and Zanger UM: Microsomal epoxide hydrolase expression as a predictor of tamoxifen response in primary breast cancer: a retrospective exploratory study with long-term follow-up. J Clin Oncol 19: 3-9, 2001.

6. Longley DB, Harkin DP and Johnston PG: 5-fluorouracil: mechanisms of action and clinical strategies. Nat Rev Cancer 3: 330-338, 2003.

7. Carreras CW and Santi DV: The catalytic mechanism and structure of thymidylate synthase. Annu Rev Biochem 64: 721-762, 1995.

8. Berger SH and Hakala MT: Relationship of dUMP and free FdUMP pools to inhibition of thymidylate synthase by 5 fluorouracil. Mol Pharmacol 25: 303-309, 1984.

9. Spears CP, Gustavsson BG, Berne M, Frosing R, Bernstein L and Hayes AA: Mechanisms of innate resistance to thymidylate synthase inhibition after 5-fluorouracil. Cancer Res 48: 5894-5900, 1988.

10. Pickard M, Dive C and Kinsella AR: Differences in resistance to 5-fluorouracil as a function of cell cycle delay and not apoptosis. Br J Cancer 72: 1389-1396, 1995.

11. Kinsella AR, Smith D and Pickard M: Resistance to chemotherapeutic antimetabolites: a function of salvage pathway involvement and cellular response to DNA damage. Br J Cancer 75: 935-945, 1997. 
12. Mader RM, Sieder AE, Braun J, et al: Transcription and activity of 5-fluorouracil converting enzymes in fluoropyrimidine resistance in colon cancer in vitro. Biochem Pharmacol 54: 1233-1242, 1997.

13. Mader RM, Muller M and Steger GG: Resistance to 5fluorouracil. Gen Pharmacol 31: 661-666, 1998.

14. Dolnick BJ: Cloning and characterization of a naturally occurring antisense RNA to human thymidylate synthase mRNA. Nucleic Acids Res 21: 1747-1752, 1993.

15. Dolnick BJ, Black AR, Winkler PM, Schindler K and Hsueh CT: rTS gene expression is associated with altered cell sensitivity to thymidylate synthase inhibitors. Adv Enzyme Regul 36: 165-180, 1996.

16. Dolnick BJ, Angelino NJ, Dolnick R and Sufrin JR: A novel function for the rTS gene. Cancer Biol Ther 2: 364-369, 2003.

17. Romain S, Spyratos F, Descotes F, et al: Prognostic of DNAsynthesizing enzyme activities (thymidine kinase and thymidylate synthase) in 908 T1-T2, N0-N1, M0 breast cancers: a retrospective multicenter study. Int J Cancer 87: 860-868, 2000.

18. Romain S, Bendahl PO, Guirou O, Malmstrom P, Martin PM and Ferno M: DNA-synthesizing enzymes in breast cancer (thymidine kinase, thymidylate synthase and thymidylate kinase): association with flow cytometric S-phase fraction and relative prognostic importance in node-negative premenopausal patients. Int J Cancer 95: 56-61, 2001

19. Ogura O, Kanzaki A, Bando H, Ogura T, Toi M and Takebayashi Y: Expression of thymidylate synthase and thymidine phosphorylase in human breast carcinoma: implication for method to detect expression of these molecules in clinic. Cancer Lett 190: 97-104, 2003.

20. Dolnick BJ and Black AR: Alternate splicing of the rTS gene product and its overexpression in a 5-fluorouracil-resistant cell line. Cancer Res 56: 3207-3210, 1996.

21. Chiou CF, Chow KC, Lin FM, Lin CK, Liu SM and Chen KY: Expression of DNA topoisomerase II $\alpha$ and multidrug resistance p-glycoprotein in acute leukemia - an immunohistochemical study. Chin Med J (Taipei) 60: 184-190, 1997.

22. Chow KC and Ross WE: Topoisomerase specific drug sensitivity in relation to cell cycle progression. Mol Cell Biol 7: 3119-3123, 1987.

23. Hsu NY, Ho HC, Chow KC, et al: Overexpression of dihydrodiol dehydrogenase as a prognostic marker of non-small cell lung cancer. Cancer Res 61: 2727-2731, 2001.

24. Challberg MD and Kelly Jr TJ: Adenovirus DNA replication in vitro. Proc Natl Acad Sci USA 76: 655-659, 1979.

25. Kaplan EL and Meier P: Nonparametric estimation from incomplete observations. J Am Stat Assoc 53: 457-481, 1958.
26. Mantel N: Evaluation of survival data and two new rank order statistics arising in its consideration. Cancer Chemother Rep 50: 163-170, 1966.

27. Lin HP, Hsu SC, Wu JC, Sheen IJ, Yan BS and Syu WJ: Localization of isoprenylated antigen of hepatitis delta virus by anti-farnesyl antibodies. J Gen Virol 80: 91-96, 1999.

28. Pagliaro L and Taylor DL: 2-Deoxyglucose and cytochalasin D modulate aldolase mobility in living $3 \mathrm{~T} 3$ cells. J Cell Biol 118 859-863, 1992.

29. Spence AM, Sheppard PC, Davie JR, et al: Regulation of a bifunctional mRNA results in synthesis of secreted and nuclear probasin. Proc Natl Acad Sci USA 86: 7843-7847, 1989.

30. Bugler B, Amalric F and Prats H: Alternative initiation of translation determines cytoplasmic or nuclear localization of basic fibroblast growth factor. Mol Cell Biol 11: 573-577, 1991

31. Feo S, Arcuri D, Piddini E, Passantino R and Giallongo A: ENO1 gene product binds to the $\mathrm{c}$-myc promoter and acts as a transcriptional repressor: relationship with Myc promoter-binding protein 1 (MBP-1). FEBS Lett 473: 47-52, 2000.

32. Michaelson D, Ahearn I, Bergo M, Young S and Philips M: Membrane trafficking of heterotrimeric $\mathrm{G}$ proteins via the endoplasmic reticulum and Golgi. Mol Biol Cell 13: 3294-3302, 2002.

33. Russo P, Ottoboni C, Malacarne D, Crippa A, Riou JF and O'Connor PM: Nonpeptidomimetic farnesyltransferase inhibitor RPR-115135 increases cytotoxicity of 5-fluorouracil: role of p53. J Pharmacol Exp Ther 300: 220-226, 2002.

34. Russo P, Malacarne D, Falugi C, Trombino S and O'Connor PM: RPR-115135, a farnesyltransferase inhibitor, increases 5-FUcytotoxicity in ten human colon cancer cell lines: role of p53. Int J Cancer 100: 266-275, 2002.

35. Miyakis S, Sourvinos G and Spandidos DA: Differential expression and mutation of the ras family genes in human breast cancer. Biochem Biophys Res Commun 251: 609-612, 1998.

36. Hussein D and Taylor SS: Farnesylation of Cenp-F is required for G2/M progression and degradation after mitosis. J Cell Sci 115: 3403-3414, 2002.

37. Adamson P, Marshall CJ, Hall A and Tilbrook PA: Posttranslational modifications of p21rho proteins. J Biol Chem 267 20033-20038, 1992.

38. Martincic I, Peralta ME and Ngsee JK: Isolation and characterization of a dual prenylated Rab and VAMP2 receptor. J Biol Chem 272: 26991-26998, 1997.

39. Fiordalisi JJ, Johnson RL II, Weinbaum CA, et al: High affinity for farnesyltransferase and alternative prenylation contribute individually to $\mathrm{K}-\mathrm{R}$ as $4 \mathrm{~B}$ resistance to farnesyltransferase inhibitors. J Biol Chem 278: 41718-41727, 2003. 